Pure Appl. Chem., Vol. 72, No. 10, pp. 1839-1849, 2000.

(C) 2000 IUPAC

\title{
Thermochemical studies of advanced nuclear fuels and materials*
}

\author{
Michio Yamawaki ${ }^{1, \dagger}$, Tadashi Inoue ${ }^{2}$, and Toru Ogawa ${ }^{3}$ \\ ${ }^{1}$ Department of Quantum Engineering and Systems Science, Graduate School of \\ Engineering, The University of Tokyo, 7-3-1 Hongo, Bunkyo-ku, Tokyo 113-8656 \\ Japan; ${ }^{2}$ Central Research Institute of Electric Power Industry (CRIEPI), Iwadokita, \\ 2-chome 11-1, Komae-shi, Tokyo 201 Japan; ${ }^{3}$ Japan Atomic Energy Research \\ Institute (JAERI), Tokai-mura, Naka-gun, Ibaraki-ken 319-11 Japan
}

\begin{abstract}
Thermochemical analyses related with development of advanced nuclear fuels (i.e., metalic, nitride, and hydride fuels) with respect to the transmutation of transuranium elements and relevant pyrochemical reprocessing and fabrication processes, which have been carried out mainly in Japan, are summarized. In addition, application of atmosphere-controlled high-temperature mass spectrometry on solid-gas reactions, in particular on the prediction of gas-interacting behaviors of cesium and lithium on respective oxide ceramics, are delineated in relation to nuclear material-relevant researches.
\end{abstract}

\section{INTRODUCTION}

With the amount of transuranium elements (TRU) being accumulated each year, innovative approaches for improved management of TRU are being sought. The use of either metallic, nitride, or hydride fuels, coupled with pyrochemical reprocessing techniques, may provide safer fast reactors for actinide burning, more economical fuel cycles, as well as the improved containment of hazardous and politically sensitive materials. As the present experience with such advanced fuels is limited, their development will be promoted by acquiring knowledge and understanding of irradiation behaviors, fabrication methods, and reprocessing techniques. Thermochemical analysis has become an important element in the development of advanced fuels and processes, particularly those involving the actinides. Other than the TRU management, thermochemical analysis has become widely utilized for evaluating the material performances in various aspects of the nuclear technology. Application of a finely tunable, atmospherecontrolled, high-temperature mass spectrometer has led to new insights into the thermochemical behaviors of high-radioactivity, fission product cesium on the occasion of a light water reactor (LWR) severe accident as well as into the lithium vapor transport behavior in ceramic breeder materials of fusion reactor blankets.

\section{METALLIC FUEL CYCLE DEVELOPMENT}

The pyro-reprocessing and the partitioning of TRUs have been developed mainly by CRIEPI and JAERI in Japan in order to recycle actinides in fast breeder reactor cycle using metal fuels. Fig. 1 shows the proposed system, which includes not only the metal fuel reprocessing with electrorefining, but also the lithium reduction of oxide fuel to make metals and reductive extraction to recover TRUs from high-level liquid waste (HLLW) originating from purex reprocessing of LWR fuels [1]. In CRIEPI, electrorefin-

\footnotetext{
*Plenary lecture presented at the $16^{\text {th }}$ IUPAC Conference on Chemical Thermodynamics (ICCT-2000), Halifax, Nova Scotia, Canada, 6-11 August 2000. Other presentations are published in this issue, pp. 1799-2082.

†Corresponding author
} 


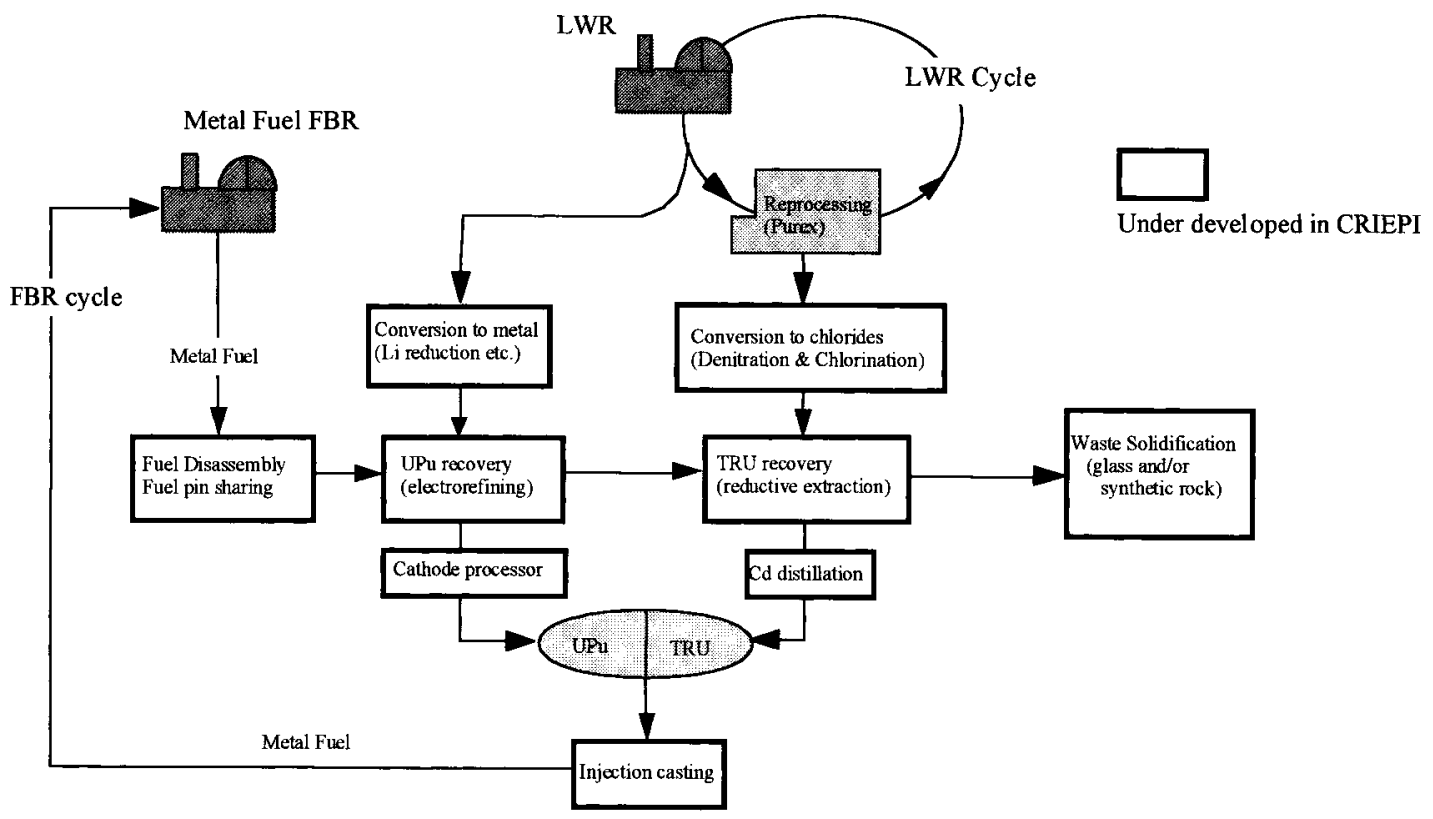

Fig. 1 Advanced nuclear fuel cycle with pyrometallurgical process connecting LWR and FBR cycles.

ing by use of a chloride salt may allow formation of uranium deposits on a solid cathode and enable TRUs to be recovered into a liquid metal cathode. This has been carried out successfully on uranium deposition at Argonne National Laboratory [2]. The reductive extraction by lithium as reductant in a system of molten chloride and liquid metal gives another device for separation of actinides. In this system, the separation of actinides from lanthanides is an attractive issue from a thermodynamic point of view. In CRIEPI, the electrochemical potentials were measured in a cell of $\mathrm{M} / \mathrm{MCl}_{\mathrm{n}}, \mathrm{LiCl}$ $\mathrm{KCl} / / \mathrm{AgCl}, \mathrm{LiCl}-\mathrm{KCl} / \mathrm{Ag}$ as a function of molar fraction of $\mathrm{MCl}_{\mathrm{n}}$ in $\mathrm{LiCl}-\mathrm{KCl}$. $\mathrm{M}$ denotes an actinide or lanthanide element. Applying the Nernst equation on the measured values of the electrochemical potentials gives the standard reduction potentials of actinides and lanthanides, as presented in Fig. 2 $[3,4]$. The potentials can be used to predict order of separation of the metals. In order to examine the separation efficiency between actinides and lanthanides by reductive extraction, the distribution coefficient of each element was measured in systems of $\mathrm{LiCl}-\mathrm{KCl} / \mathrm{Cd}$ and $\mathrm{LiCl}-\mathrm{KCl} / \mathrm{Bi}$ at $450-500{ }^{\circ} \mathrm{C}$, from which the separation factor between actinide and lanthanide is obtained, as shown in Fig. 3 [5,6]. The figure indicates that $\mathrm{LiCl}-\mathrm{KCl} / \mathrm{Bi}$ system has a higher separation potential than $\mathrm{LiCl}-\mathrm{KCl} / \mathrm{Cd}$ system.

Following the measurements of electrochemical potentials and distribution coefficients, separation tests of actinides have been carried out by electrorefining and reductive extraction. The liquid cadmium cathode containing $4.7 \mathrm{wt} \%$ of plutonium was obtained by electrorefining through the joint study of CRIEPI and JAERI. Plutonium formed an intermetallic compound with cadmium due to the poor solubility in cadmium. The separation of TRUs from lanthanides was examined for the aim of recovering actinides from HLLW, in which lanthanides exist in ca. 10 times more amount than actinides.

It is suggested from Fig. 3 that the multistage extraction is required even in the system of $\mathrm{LiCl}-\mathrm{KCl} / \mathrm{Bi}$ to attain the requirement for the ratio of the transuranium elements/lanthanides, to be more than unity. The requirement arises from both aspects of the allowable amount of minor actinides, neptunium, americium, and curium, in metal fuel $\mathrm{U}-\mathrm{Pu}-\mathrm{Zr}$ and of the reactor physics calculation. The separation experiment indicates the good separation from lanthanides with removal of each actinide by more than $99.3 \%$ from $\mathrm{LiCl}-\mathrm{KCl}$ salt into liquid bismuth, whose results are identical with the estimation from separation factors, as shown in Table 1 [5]. 


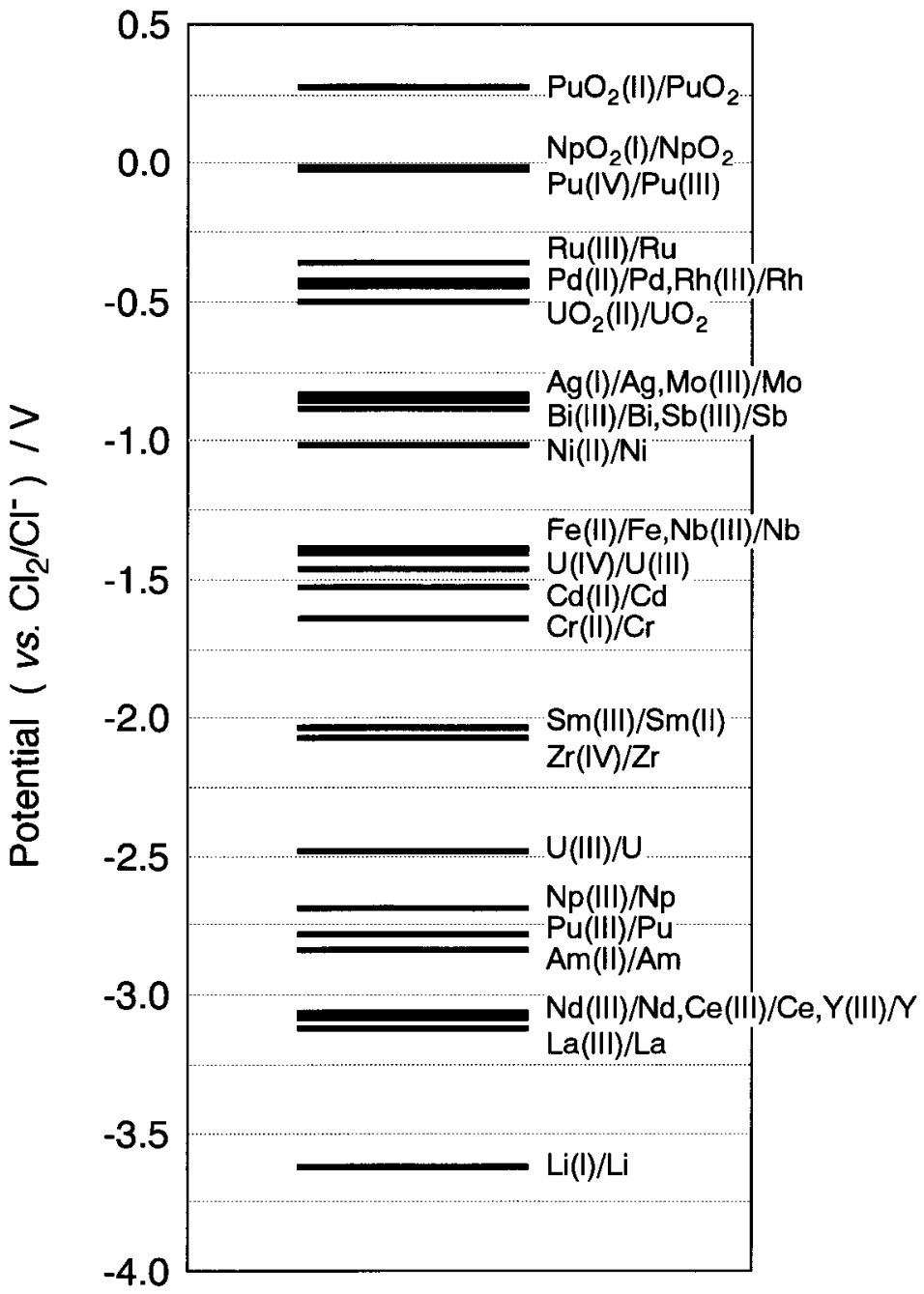

Fig. 2 Standard potential in $\mathrm{LiCl}-\mathrm{KCl}$ eutectic at $450{ }^{\circ} \mathrm{C}$.
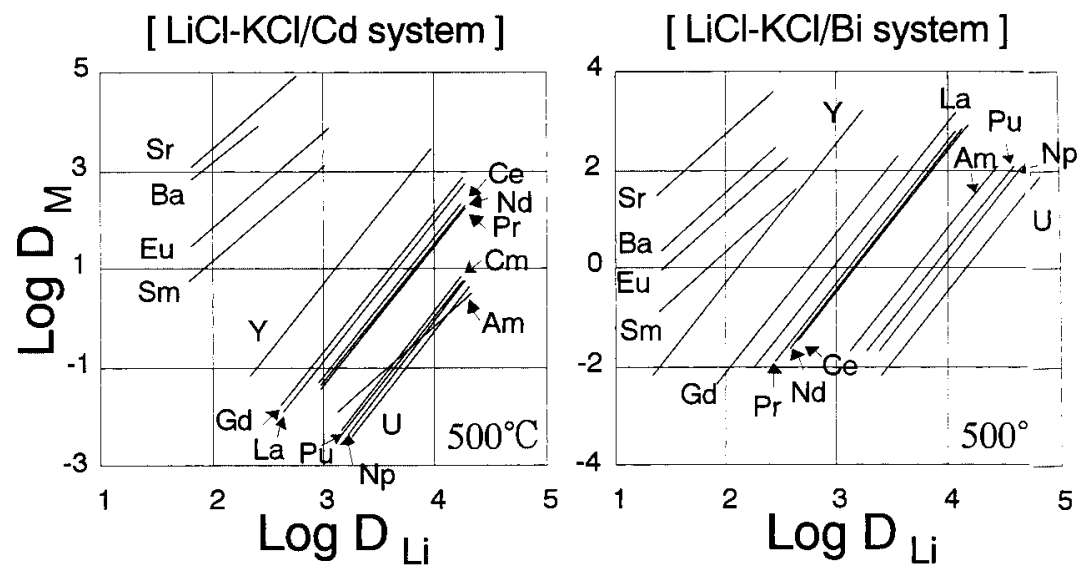

Fig. 3 Distribution coefficients for actinides, rare-earths, and alkaline-earths with respect to distribution coefficient of Li.

(C) 2000 IUPAC, Pure and Applied Chemistry 72, 1839-1849 
Table 1 Separation of actinides from lanthanides with recovery yield by means of multiple batch extraction in $\mathrm{LiCl}-\mathrm{KCl} / \mathrm{Bi}$ system at $500{ }^{\circ} \mathrm{C}$.

(a) Recovery yield of each element after 5 steps

\begin{tabular}{ccc}
\hline element & \multicolumn{2}{c}{ experiment } \\
\hline $\mathrm{U}$ & 99.30 & $100 \quad$ (\%) \\
$\mathrm{Np}$ & 99.93 & 99.998 \\
$\mathrm{Pu}$ & 99.94 & 99.987 \\
$\mathrm{Am}$ & 99.66 & 99.815 \\
$\mathrm{Pr}$ & 20.94 & 21.534 \\
$\mathrm{Ce}$ & 20.54 & 18.615 \\
$\mathrm{Nd}$ & 16.34 & 17.121 \\
$\mathrm{La}$ & 6.85 & 6.565 \\
$\mathrm{Gd}$ & 7.52 & 1.723 \\
\hline
\end{tabular}

(b) Weight ratio of recovered TRUs to REs in each step

\begin{tabular}{ccc}
\hline stages & \multicolumn{2}{c}{ experiment calculation } \\
\hline \#1 & 1.48 & 1.45 \\
$\# 2$ & 0.81 & 0.79 \\
$\# 3$ & 0.57 & 0.53 \\
$\# 4$ & 0.43 & 0.39 \\
$\# 5$ & 0.32 & 0.30 \\
\hline
\end{tabular}

The actinides are recycled into metal fuel for fast breeder reactors. The phase diagram predicts a low limited solubility of trivalent species in $\mathrm{U}-\mathrm{Pu}-\mathrm{Zr}$ matrix [7]. U-Pu-Zr alloys added with minor actinides of $2 \mathrm{wt} \%$ and $5 \mathrm{wt} \%$ each and lanthanides of $2 \mathrm{wt} \%$ and $5 \mathrm{wt} \%$ each were casted in order to evaluate the miscibility between trivalent species and $\mathrm{U}-\mathrm{Pu}-\mathrm{Zr}$. Metallography shows the intermetallic compound of americium, neodymium, and cerium distributing uniformly at grain boundaries [8]. The solubility of trivalent species in $\mathrm{U}-\mathrm{Pu}-\mathrm{Zr}$ is less than $1 \mathrm{wt} \%$ even at melting state, as observed in EPMA analysis. For use of the metal alloy as a nuclear fuel, modification of the fundamental properties, such as melting temperature, elastic modulus, and redistribution of components under a temperature gradient, has to be clarified on alloys of U-Pu-Zr to which minor amounts of actinides and lanthanides are added [9]. It was observed that the properties of the alloys with minor amounts of added actinides and lanthanides up to $5 \mathrm{wt} \%$ each are approximately the same as those of $\mathrm{U}-\mathrm{Pu}-\mathrm{Zr}$. The liquefaction temperature by eutectic formation of $\mathrm{U}-\mathrm{Pu}-\mathrm{Zr}$ fuel and stainless steel cladding is expected to be above $600{ }^{\circ} \mathrm{C}$, which affects directly the reactor operation temperature. The liquefaction was evaluated from diffusion tests using $\mathrm{U}-\mathrm{Pu}-\mathrm{Zr} / \mathrm{Fe}$ couple, and the phase diagrams were assessed both by thermodynamic calculation and metallography [10]. The diffusion tests indicate that no melting phase appears under $650{ }^{\circ} \mathrm{C}$ in a region with less than $25 \mathrm{wt} \%$ of plutonium in fuel U-Pu [11]. The thermodynamic calculation of the activity gradient explains the mechanism of liquefaction, namely the diffusion paths through a two-phase region of liquid and $\mathrm{U}_{6} \mathrm{Fe}$, provided that a cladding temperature is greater than $650{ }^{\circ} \mathrm{C}$.

\section{NITRIDE FUEL DEVELOPMENT}

The high-temperature chemistry research on actinide nitrides has been performed mainly by JAERI in Japan. One of the advantages of the nitride fuels for transmutation is the mutual miscibility among the actinide mononitrides. This advantage is considered to be important, since the mutual solubility between lighter actinides (U-Np) and heavier trivalent actinides (Am-Cm) is limited in the alloys [12]. A greater flexibility is desirable in designing the dedicated actinide-burning core, where the isotope vector of the actinides varies significantly with the spent fuel history from the commercial reactors. The variation in actinide composition in a fuel type may bring about a significant change in its properties.

Solid solutions among UN, NpN, and PuN have been extensively studied by Arai et al. of JAERI [13]. Good mutual solubility was obtained among those nitrides, as expected from the very small difference in the lattice parameter (Fig. 4). The remaining question was the mutual solubility between the nitrides of lighter actinides (U-Pu) and heavier ones $(\mathrm{Am}, \mathrm{Cm})$. The atomic-number dependence of molar volume of actinide mononitrides somewhat reflects that of pure metallic state: There is a notice- 
able gap at the crossing from $\mathrm{Pu}$ to Am, although the gap is not so significant as that found for the pure metals. In addition, the mutual solubility and the fabrication homogeneity of the nitrides of actinides and some transition metals have to be studied. In the accelerator-driven transmutation system, the fuel would consist of actinide nitrides dispersed or dissolved in a neutronically inert matrix. The mutual miscibility among the actinide mononitrides has been demonstrated recently in the fabrication of $(\mathrm{Cm}$, $\mathrm{Pu}) \mathrm{N}$ by Takano et al. [14]. The $\left(\mathrm{Cm}_{0.4} \mathrm{Pu}_{0.6}\right) \mathrm{O}_{2}$ was successfully converted to the mixed mononitrides by the carbothermic synthesis in a gas stream of nitrogen and hydrogen. This behavior is in strong contrast to the metal alloys where $\mathrm{Cm}$ and $\mathrm{Pu}$ are almost immiscible. The thermodynamic consideration is involved in the preparation, that is, the relative stability of actinide carbides, nitrides, and oxides (Fig. 5). The recent data by Arai et al. suggests that $\Delta \mathrm{G}_{\mathrm{f}}{ }^{\mathrm{o}}(\mathrm{NpN}) \sim \Delta \mathrm{G}_{\mathrm{f}}{ }^{\mathrm{o}}(\mathrm{UN})$ [13]. The $\Delta \mathrm{G}_{\mathrm{f}}{ }^{\mathrm{o}}$ (AmN) as estimated from the Am vaporization behavior in a reactor-grade $\mathrm{PuN}$ is also not much different from that of mononitrides of lighter actinides [13]. With increasing atomic number, the stability of carbides decreases, but that of the nitrides appears to be rather constant.

It is not easy to remove carbon in producing nitride of the lighter actinide by carbothermic synthesis. However, the carbides would become less stable for Am [16] and probably Cm. Rather, as expected from Fig. 5, it would be harder to remove oxygen from the nitrides of the latter elements. Takano et al. [15] used a carbon-excess environment to prepare the single-phase $(\mathrm{Cm}, \mathrm{Pu}) \mathrm{N}$. The degree of carbon excess in the raw mixture might have been a little too large, but this was inevitable to assure the better contact between the oxide and carbon particles for a tiny amount of the sample $(\sim 30 \mathrm{mg})$. The oxygen contents of the products have not been analyzed yet, but the relative contents could be judged from the lattice parameter. It should be noted that the lattice parameter of $\mathrm{MN}$ increases with increasing oxygen content for $\mathrm{U}, \mathrm{Pu}$, and $\mathrm{Am}$; the effect is the reverse of that found on the lanthanides. The similar effect is expected for $\mathrm{Cm}$ also. The lattice parameter of the apparently oxide-free product was $0.4948 \mathrm{~nm}$, which is even smaller than that expected from those of PuN $(0.4905 \mathrm{~nm})$ and $\mathrm{CmN}(0.5041$ $\mathrm{nm})$ in the literature.

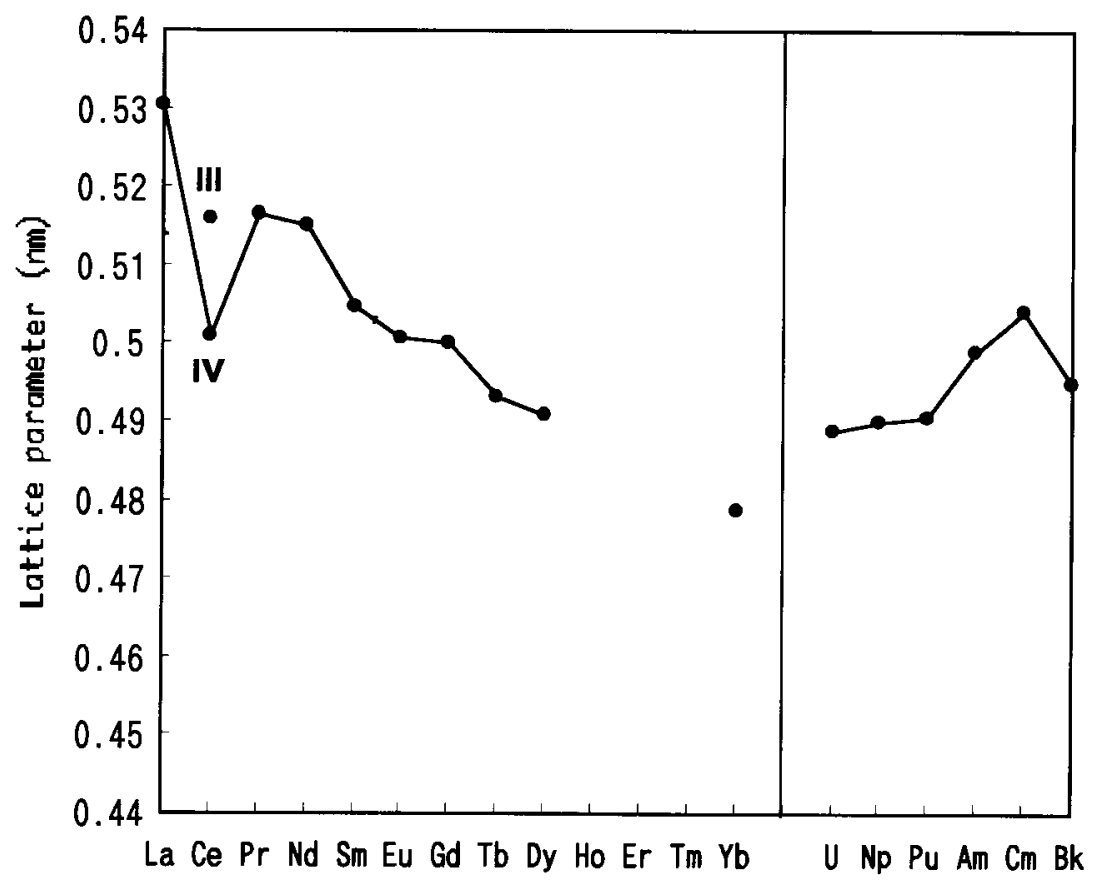

Fig. 4 Lattice parameters of mononitrides of lanthanides and actinides.

(C) 2000 IUPAC, Pure and Applied Chemistry 72, 1839-1849 
The irradiated nitride fuels will be subjected to the molten-salts electrorefining process to remove the fission products. So far, the molten-salts electrolysis of single-phases UN, NpN, and PuN has been studied [13,17-19]. The apparent decomposition potentials are summarized in Table 2. Those decomposition potentials differ significantly from the simple theoretical prediction: The decomposition potential vs. $\mathrm{Ag} / \mathrm{Ag}^{+}$reference electrode may be estimated by

$$
E_{0}=\left[\Delta G_{\mathrm{f}}{ }^{0}\left(\mathrm{PuCl}_{3}\right)-\Delta G_{\mathrm{f}}{ }^{0}(\mathrm{PuN})\right] / 3 F-\left[\Delta G_{\mathrm{f}}{ }^{0}(\mathrm{AgCl})+R T \ln a(\mathrm{AgCl})\right] / F
$$

where one assumes that PuN decomposes at a nitrogen partial pressure $\left(p\left(\mathrm{~N}_{2}\right)\right)$ of $1 \mathrm{~atm}(0.1013 \mathrm{MPa})$, and the activity of $\mathrm{PuCl}_{3}$ is unity at the nitride/salts interface. In the anodic dissolution, the potential is raised from the rest potential. The activity of $\mathrm{PuCl}_{3}$ at the solid/molten-salts interface should become higher than that in the bulk salts and should increase with the potential until it reaches a limiting concentration $[19,20]$. In the case of $\mathrm{UN}$, the ternary compound $\mathrm{UNCl}$ is formed as a by-product at the anode [22], which would adversely affect the efficiency of uranium recovery. The formation of insoluble ternary compound $\mathrm{MNCl}$ may be neglected for transuranium elements. Actually, the concentration of $\mathrm{Pu}$ in the molten salts remained almost constant during the electrolysis of PuN [19].

Another research area concerns the transuranium elements in low melting-point alloys, which may be used as the cathode in the above process. The Am-Cd binary system has been investigated by Hayashi et al. [23]. The nature of the intermetallic compounds in the system has been defined. The alloy of $\mathrm{Cd} / \mathrm{Am}=30$ was heated at $673 \mathrm{~K}$, and then excess $\mathrm{Cd}$ was distilled away at the same temperature under a temperature gradient. The X-ray diffraction (XRD) pattern was best explained by the existence of two compounds, $\mathrm{Am}_{11} \mathrm{Cd}_{45}$, or mixture of $\mathrm{AmCd}_{3}$ and $\mathrm{AmCd}_{6}$. While $\mathrm{MCd}_{11}$-type compound is the most Cd-rich intermediate phase for $\mathrm{U}-\mathrm{Pu}$ and $\mathrm{La}-\mathrm{Sm}$, the indication of its existence for $\mathrm{Am}-\mathrm{Cd}$ phase has not been obtained in the experimental condition. The $\mathrm{Cd}$ was further removed by heating the alloy above $873 \mathrm{~K}$; the $\mathrm{Cd}$ content in the remaining Am metal was 0.15 at \%.

The structural characteristics of $\mathrm{M}^{3+}-\mathrm{X}^{-}$complex are important in determining the stabilization of the trivalent actinides and lanthanides in the molten halides. This aspect is being studied by coupling the structural analyses of the molten salts and the molecular dynamics simulation. The structure of the molten salts is investigated by high-temperature XRD as well as extended X-ray absorption fine structure (EXAFS). From the MD simulation, it was found that the partial molar enthalpy of mixing of the $\mathrm{LnX}_{3}$ (Ln:lanthanides) in $\mathrm{AX}$ (A:alkali metal) mixtures is correlated with the stability of the $\mathrm{LnX}_{6}^{3-}$ octahedron [24]. In the pure $\mathrm{LnX}_{3}$, it is hard to maintain the octahedral complex in good shape, due to the overall deficiency of $\mathrm{X}^{-}$. The addition of $\mathrm{ACl}$ compensates this halide-ion deficiency, and hence stabilizes $\mathrm{LnX}_{6}{ }^{3-}$. Hitherto, the structural characteristics of these molten materials were mostly viewed with the metal ions at the center. The EXAFS makes it possible to view it from the other way around: we can view it with the anion in the center also. In this way, we can better understand the role of the anions bridging the $\mathrm{LnX}_{6}^{3-}$ octahedrons. Figure 6 shows results of EXAFS measurements on solid and

Table 2 Experimental decomposition potential of actinide nitrides at $773 \mathrm{~K}$.

\begin{tabular}{|c|c|c|l|}
\hline Nitride & $\begin{array}{c}\text { Decomposition potential } \\
\text { (vs. Ag/AgCl }\end{array}$ & E by eq.(1) & \multicolumn{1}{|c|}{ Remark } \\
\hline $\mathrm{UN}$ & -0.44 & -0.44 & $\begin{array}{l}\text { UN is covered by UNCl during anodic } \\
\text { polarization. }\end{array}$ \\
\hline $\mathrm{NpN}$ & -0.76 & $(-0.45)^{* * *}$ & - \\
\hline $\mathrm{PuN}$ & -0.88 & -0.63 & - \\
\hline
\end{tabular}

* Normalized to $\mathrm{AgCl}(0.39 \mathrm{~mol} \%)$ in $\mathrm{LiCl}-\mathrm{KCl}$ eutectic melt.

** $\Delta \mathrm{G}_{\mathrm{f}, 773^{\prime \prime}}(\mathrm{NpN})$ is assumed to be the same as that of $\mathrm{UN}$. 


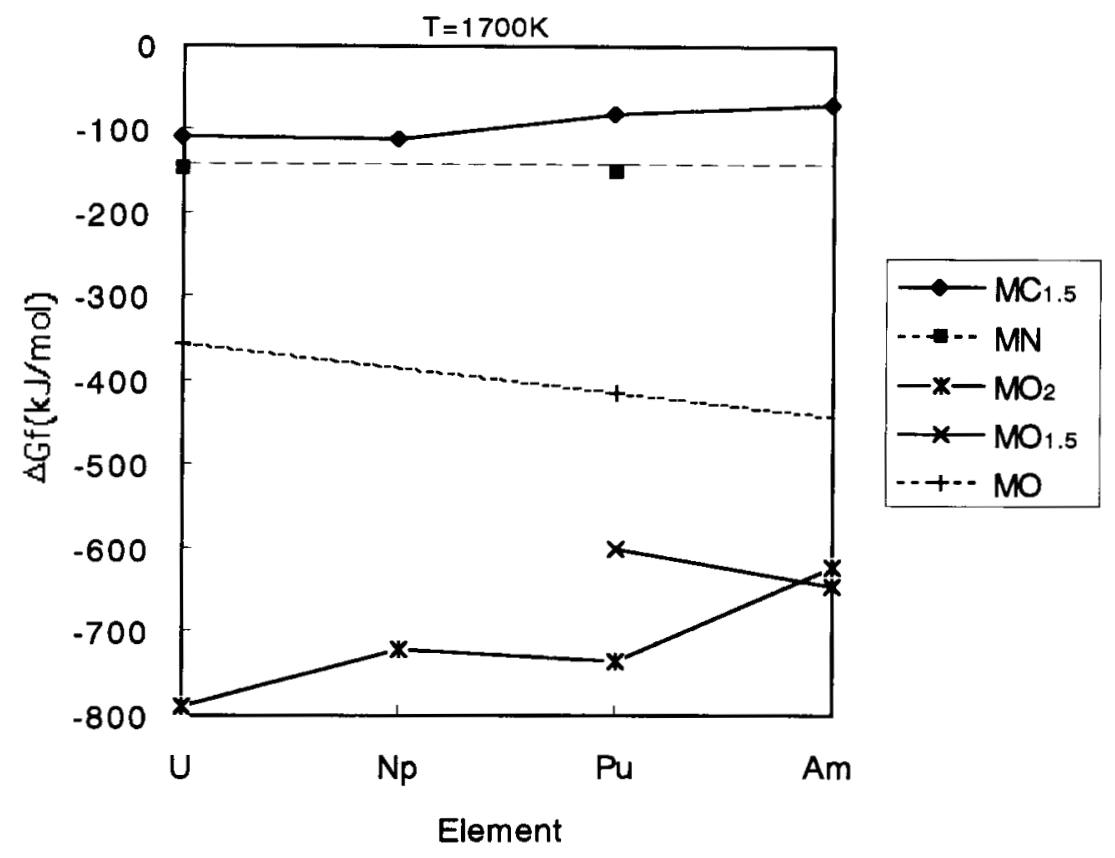

Fig. 5 Free energy of formation of carbide, nitride, and oxides of actinide elements.

molten $\mathrm{LaBr}_{3}$, as well as molten $\mathrm{LaBr}_{3}-\mathrm{LiBr}$ [25]. At melting of $\mathrm{LaBr}_{3}$, the coordination number of $\mathrm{La}^{3+}$ around $\mathrm{Br}^{-}$is significantly reduced to nearly 2, indicating that the most of $\mathrm{Br}^{-}$becomes a bridging ion connecting $2 \mathrm{LaBr}_{6}{ }^{3-}$ octahedra. The addition of $\mathrm{LiBr}$ further reduces this coordination number by $30-40 \%$, since the sharing of $\mathrm{Br}^{-}$among octahedra became less important, owing to the additional $\mathrm{Br}^{-}$ brought with the $\mathrm{LiBr}$.

\section{HYDRIDE FUEL DEVELOPMENT}

Compared to the studies on metallic and nitride fuels, those on actinide hydride as a nuclear fuel have been much more scarce. The hydride fuel has been studied by the researchers in the University of Tokyo in collaboration with Tohoku University. The studies on hydrogeneration of uranium alloys [26-28] have led to a possibility of a new MA-containing hydride fuel which may be used as MA transmutating target material [29]. The merit of this target material would be to attain the best transmutation rate of MA with improved safety characteristics of a fast reactor core.

The experiments done so far on the hydride fuel have been for the hydrogenated $\mathrm{U}-\mathrm{Th}-\mathrm{Zr}$ alloy. Figure 7 shows the hydrogen desorption characteristics of $\mathrm{UThZr}_{4}$-hydrogen system at $1173 \mathrm{~K}$ [29]. The slowly ramping slope in the left side of the curve in Fig. 7 corresponds to the homogeneous $\mathrm{ThZr}_{2} \mathrm{H}_{7-\mathrm{X}}$ phase, while the plateau at the right-hand side corresponds to the $\mathrm{ZrH}-\mathrm{ZrH}_{1,4}$ equilibrium at around $90 \mathrm{kPa}$. The hydrogenated $\mathrm{U}-\mathrm{Th}-\mathrm{Zr}$ alloy was found to be composed of fine grains of a metal uranium phase and $\mathrm{ZrH}_{2-x}$ phase and the dominant $\mathrm{ThZr}_{2} \mathrm{H}_{7-\mathrm{x}}$ phase. The hydrogenated ternary alloy was irradiated in the Japan Material Testing Reactor (JMTR) in JAERI, which then underwent post-irradiation examinations. The important thermochemical/thermophysical properties of this hydrided alloy, such as the heat capacity, thermal expansion coefficient, thermal diffusivity, etc., have been measured, which proved this material to be suitable for the target material . 


\section{APPLICATION OF ATMOSPHERE-CONTROLLED, HIGH-TEMPERATURE MASS SPECTROMETRY}

A finely tunable atmosphere-controlled, high-temperature mass spectrometer has been developed and used for high-temperature solid-gas equilibrium studies in the University of Tokyo by Yamawaki et al. [30-34]. The controllability of the gas inlet system installed in this mass spectrometer has been examined by introducing deuterium gas, where the obtained $\mathrm{D}_{2}$ pressure in Knudsen cell plotted vs. reciprocal temperature has been shown to be approximately identical with the theoretical curve as shown in Fig. 8. Using this apparatus, the cesium vapor pressure over either $\mathrm{Cs}_{2} \mathrm{UO}_{4}$ or $\mathrm{Cs}_{2} \mathrm{U}_{4} \mathrm{O}_{12}$ was measured under a controlled flow of low pressure $\mathrm{D}_{2}$ or $\mathrm{D}_{2}+\mathrm{O}_{2}$ gas, simulating a severe LWR accident. The cesium pressure over $\mathrm{Cs}_{2} \mathrm{UO}_{4}$ was strongly affected by the oxygen potential of the atmosphere as shown in Fig. 9, while that over $\mathrm{Cs}_{2} \mathrm{U}_{4} \mathrm{O}_{12}$ was little influenced [31]. Such a striking contrast between the vaporization behaviors of these mixed oxides was explained from the possible buffering effect by $\mathrm{UO}_{2+\mathrm{X}}$ in the case of $\mathrm{Cs}_{2} \mathrm{U}_{4} \mathrm{O}_{12}$, while no such effect was expected for $\mathrm{Cs}_{2} \mathrm{UO}_{4}$. On the other hand, the lithium vapor losses from solid oxide breeder materials under a flow of hydrogen-added helium sweep gas were evaluated by measuring lithium vapor pressures in the above system. Among several solid oxide breeders tested, $\mathrm{Li}_{4} \mathrm{SiO}_{4}$ showed a strong dependence of lithium vapor loss upon the oxygen potential of the system. This behavior was attributed to the nonstoichiometry of $\mathrm{Li}_{4} \mathrm{SiO}_{4}$. This explanation has been supported by the work function change measurement using a high-temperature Kelvin probe by the same anthors [34].

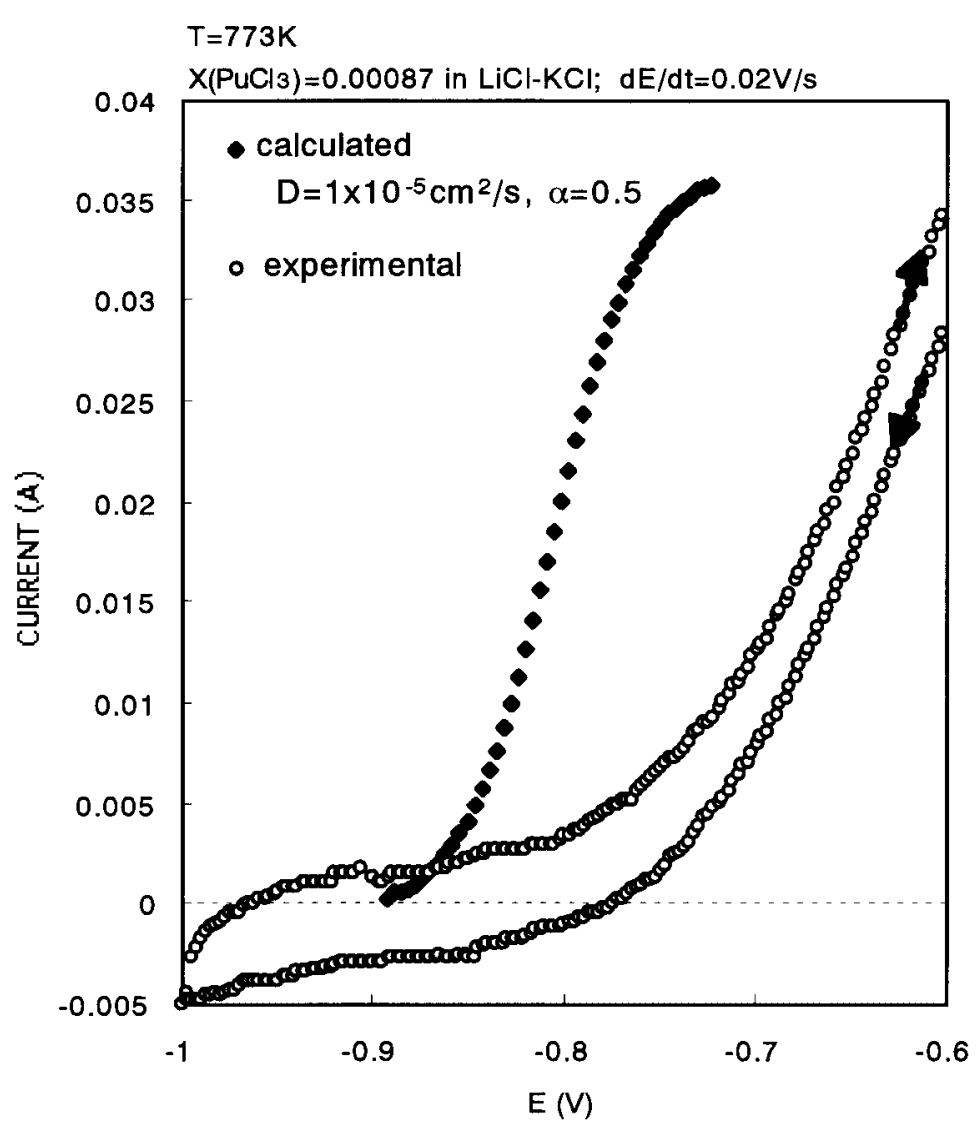

Fig. 6 Experimental anodic polarization curve compared with the result of numerical analysis. 


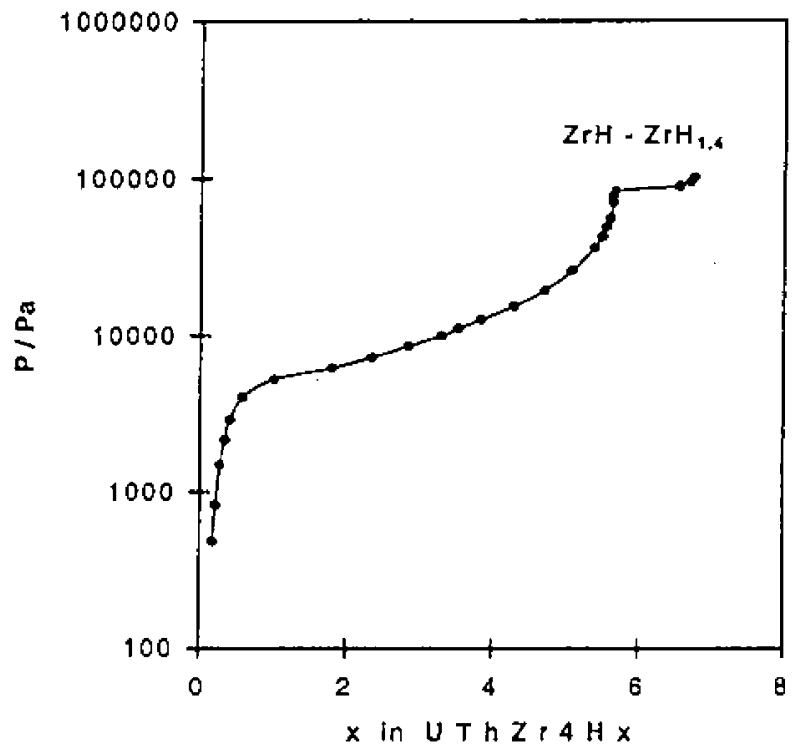

Fig. 7 Hydrogen pressure-composition isotherm of alloy with U:Th:Zr:H ratio of 1:1:4:9.5 at $1173 \mathrm{~K}$.

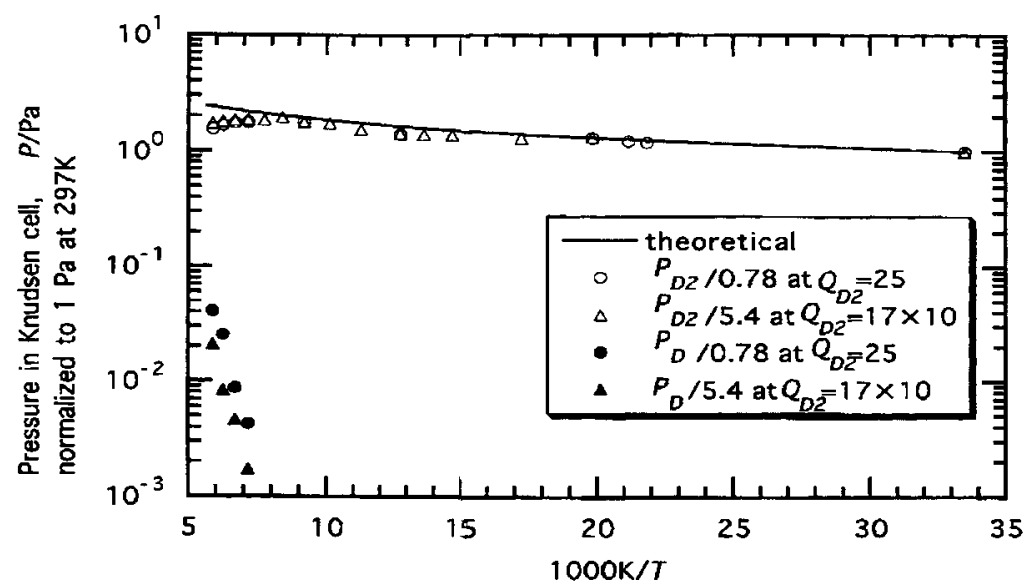

Fig. 8 Temperature dependence of gas pressure in Knudsen cell with gas introduction at fixed flow rate $Q_{D 2} / 10^{-6} \mathrm{~Pa} \mathrm{~m}^{3} \mathrm{~s}^{-1}$.

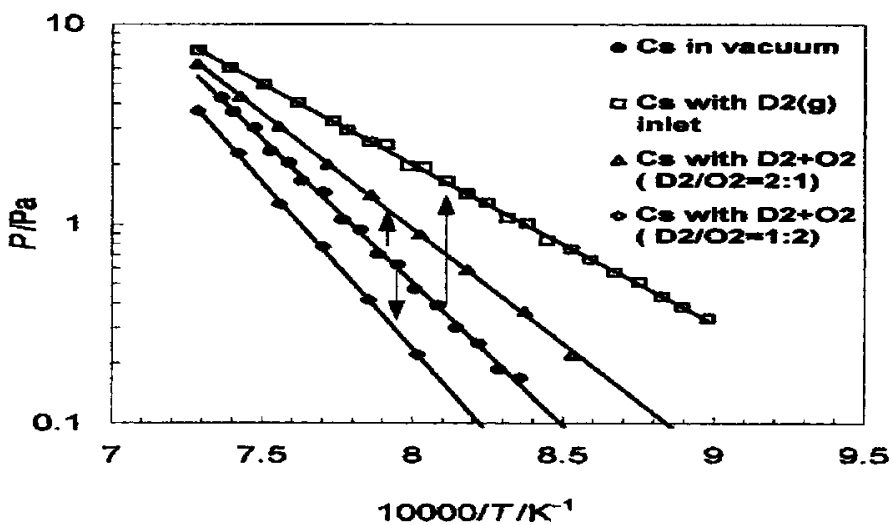

Fig. 9 Comparison of Cs pressure over $\mathrm{Cs}_{2} \mathrm{UO}_{4}$ in different conditions.

(C) 2000 IUPAC, Pure and Applied Chemistry 72, 1839-1849 


\section{CONCLUSION}

As advanced nuclear fuels, metallic and nitride fuels have been analyzed thermochemically and shown to be promising candidates for fast breeder reactor fuels with a high capability of transmutating the TRU elements. Also, the hydride fuel has been analyzed and shown to be capable of effective transmutation of TRU with improved safety characteristics of fast reactor core. In addition, a highly tunable, atmosphere-controlled, high-temperature mass spectrometer has been developed and demonstrated to be extremely useful in the investigation of the high-temperature thermochemical equilibiria of solid-gas interactions. Its application to some nuclear material problems, in particular LWR accident analysis and fusion reactor ceramic breeder behavior analysis, has been fully demonstrated with success.

\section{REFERENCES}

1. T. Inoue and H. Tanaka. Proc. Internat. Conf. on Future Nuclear Systems (GLOBAL'97), pp. 646-652, Oct. 5-10, Yokohama, Japan (1997).

2. M. J. Steiner, P. A. Nelson, J. E. Battles, P. W. Green. Chemical Technology Division Annual Technical Report 1990, ANL-91, 18, (May 1991).

3. Y. Sakamura, T. Hijikata, K. Kinoshita, T. Inoue, T. S. Storvick, C. L. Krueger, J. J. Roy, D. L. Grimmett, S. P. Fusselman, R. L. Gay. J. Alloys Comp. 592, 271-273 (1998).

4. J. A. Plambeck. "Fused salt systems" In Encyclopedia of Electrochemistry of the Elements Vol. X, A. J. Bard (Ed.), Marcel Dekker, New York and Basel (1976).

5. K. Kinoshita, T. Inoue, S. P. Fusselman, D. L. Grimmett, J. J. Roy, R. L. Gray, C. L. Krueger, C. R. Nabelek, T. S. Storvick. J. Nucl. Sci. Tecnol. 36, 189 (1999).

6. M. Kurata, Y. Sakamura, T. Hijikata, K. Kinoshita. J. Nucl. Mater. 227, 110 (1995)

7. T. B. Massalski (Ed.). Binary alloy phase diagram $2^{\text {nd }}$ ed., ASM International (1990).

8. T. Inoue, M. Murata, L. Koch, J-C. Spirlet, C. T. Walker, C. Sari. Trans. Am. Nucl. Soc. 64, 552 (1991).

9. M. Kurata, T. Inoue, L. Koch. CRIEPI-Report T92005 (1992) (in Japanese).

10. M. Kurata, K. Nakamura, T. Ogata. Proc. of $10^{\text {th }}$ Symposium on Thermodynamics of Nuclear Materials, Halifax, Nova Scotia, Canada, Aug. 6-11, 2000.

11. K. Nakamura, T. Ogata, M. Kurata, T. Yokoo, M. A. Mignanelli. J. Nucl. Sci. Technol. In press.

12. T. Ogata, M. Akabori, F. Kobayashi, R. G. Haire. J. Nucl. Mater. 247, 215-221 (1997).

13. Y. Arai, T. Iwai, K. Nakajima, O. Shirai, Y. Suzuki. "Experimental research on nitride fuel cycle in JAERI", Proc. of Internat. Conf. on Future Nuclear Systems (GLOBAL'99), Jackson Hole, Wyoming, USA, Aug. 29-Sept. 3, 1999.

14. M. Takano, A. Itoh, M. Akabori, T. Ogawa, M. Numata, H. Okamoto. "Carbotheramic synthesis of $(\mathrm{Cm}, \mathrm{Pu}) \mathrm{N}$ ", Proc. of $10^{\text {th }}$ Symposium on Thermodynamics of Nuclear Materials, Halifax, Nova Scotia, Canada, Aug. 6-11, 2000.

15. T. Ogawa, T. Ohmichi, A. Maeda, Y. Arai, Y. Suzuki. J. Alloys Comp. 224, 55-59 (1995).

16. C. E. Holley, Jr., M. H. Rand, E. K. Storms. The Chemical Thermodynamics of Actinide Elements and Compounds, Part 6, The Actinide Carbides, IAEA, Vienna (1984).

17. M. Akabori, M. Takano, 30iemes Jourees des Actinides, May 4-6, 2000, Dresden, Germany.

18. F. Kobayashi, T. Ogawa, M. Akabori, Y. Kato. J. Am. Ceram. Soc. 78, 2779 (1995).

19. O. Shirai, T. Iwai, K. Shiozawa, Y. Suzuki, Y. Sakamura, T. Inoue. J. Nucl. Mater. 277, 226-230 (2000).

20. T. Ogawa, Y. Okamoto, R. J. M. Konings. In Innovative Materials in Advanced Energy Technologies, P. Vincenzini (Ed.), Techna Srl. (1999).

21. D. K. Gosser, Jr. In Modern Techniques in Electroanalysis, P. Vanysek (Ed.), ch. 7, Wiley, New York (1996). 
22. F. Kobayashi, T. Ogawa, Y. Okamoto, M. Akabori. J. Alloys Comp. 271-273, 374-377 (1998).

23. H. Hayashi, T. Sato, T. Ogawa, R. G. Haire. Proc. Internat. Conf. on Future Nuclear Systems (GLOBAL'99), Jackson Hole, Wyoming, Aug. 29- Sept. 3, 1999.

24. Y. Okamoto and T. Ogawa. Z. Naturforsch 54a, 599-604 (1999).

25. Y. Okamoto, M. Akabori, H. Motohashi, T. Ogawa. $11^{\text {th }}$ Internat. Conf. on X-ray Absorption Fine Structure (XAFS11), Ako, Japan, July 2000.

26. T. Yamamoto, H. Kayano, H. Suwarno, M. Yamawaki. J. Alloys Comp. 213-214, 467-470 (1994).

27. H. Suwarno, T. Yamamoto, F. Ono, K. Yamaguchi, M. Yamawaki. J. Nucl. Mater. 247, 333-338 (1997).

28. T. Yamamoto, H. Suwarno, H. Kayano, M. Yamawaki. J. Nucl. Mater. 247, 339-344 (1997).

29. M. Yamawaki, H. Suwarno, T. Yamamoto, T. Sanda, K. Fujimura, K. Kawashima, Y. Suzuki. J. Alloys Comp. 271-273, 530-533 (1998).

30. M. Yamawaki, A. Suzuki, M. Yamamoto, K. Yamaguchi. J. Nucl. Mater. 223, 80-83 (1995).

31. M. Yamawaki, K. Yamaguchi, J. Huang, M. Yasamoto, F. Ono, H. Sakura, M. Hirai, J. Sugimoto, Y. Suzuki. J. Mass Spectrom. Soc. Jpn. 47, 16-22 (1999).

32. M. Yamawaki, M. Yasumoto, K. Yamaguchi. J. Mass Spectrom. Soc. Jpn. 47, $54-57$ (1999).

33. J. Huang, M. Yamawaki, K. Yamaguchi, F. Ono, M. Yasumoto, H. Sakurai, J. Sugimoto. J. Nucl. Mater. 270, 259-264 (1999).

34. A. Suzuki, K. Yamaguchi, M. Yamawaki. Fusin Engineering and Design, 39-40, 699-705 (1998). 